\title{
DIALOGUE \\ Industry is Not the Enemy
}

Judith (Judy) Totman Parrish, Dept. of Geological Sciences, Mines 322, University of Idaho, Moscow, Idaho 83844-3022, USA; jparrish@uidaho.edu

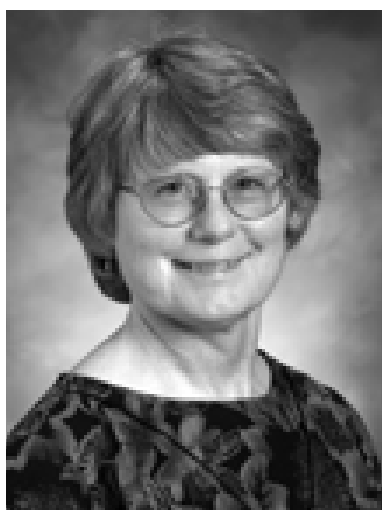

Judy Parrish
Recently, GSA Headquarters staff and officers have received what seems to be an increasing number of complaints from our members regarding our associations with industry, particularly the resources industry. I don't want to paint with too broad a brush, but the gist of some of these remarks seems to be that these industries are inherently evil and that GSA should have nothing to do with them. The opinion seems to be that, by associating themselves with GSA, these "dirty" companies are attempting to "greenwash" themselves. Recently, this was discussed within the Executive Committee, and we are in agreement that these complaints represent a disturbing trend that threatens both the Society and, indeed, our entire profession. Thus, it falls to me, as your president, to explain why and to ask that you make yourselves more aware of how industry operates and how our association with industry has been and should continue to be beneficial to us, to industry, and, ultimately, to society.

In some ways, I'm finding it hard to devolve some of the issues, because in a very real way, industry is part of us, regardless of sponsorships, advertisements, and booths in the exhibit hall at the annual meeting. It's a little like saying that I'm going to analyze the functioning of an arm independent of the health of the rest of the body. But here are some observations:

1. Many GSA members work for companies, both private and public. You know a lot of them. Ask them sometime about how they like their jobs, how they feel about working for industry. You might be surprised at the answer. A friend of mine, an engineer and project manager, works for one of the largest oil companies. She is proud of the company and its approach to business around the world, the way it respects the world's many cultures, offering both goods and financial assistance in natural disasters, supporting education, and being circumspect in looking for and delivering on ways to develop Earth's resources. Her company provides thousands of jobs to people here as well as in the poorest and neediest parts of the world. And the company demonstrated flexibility and care for her by supporting her very sensitively when her husband underwent a long-term terminal illness.
How far the petroleum industry has come in minimizing environmental impacts was outlined by ecologist Jared Diamond in his 2004 book, Collapse, in which he noted that, to his surprise, the footprint of an oil rig in environmentally sensitive New Guinea was extremely small.

2. Most of the largest companies, which seem to be the objects of much of the ire, are public companies. The petroleum industry is currently running an advertisement that many of us might not like, but which is accurate: very large portions of these companies are owned by members of the public, including GSA members. Those of us with retirement savings in diversified stock funds own parts of these companies and have benefited from their profits. Indeed, in the current financial crisis, the resource industries are keeping our funds from sliding even further-we will be that much less dependent on our fellow taxpayers for our well-being in retirement, so that scarce tax resources can be used to help those who are truly in need.

3. A large proportion of our students end up working in industry. The just-released report by the American Geophysical Institute (AGI) on geosciences employment sectors indicates that $21 \%$ of recent M.S. degree recipients and $3 \%$ of recent Ph.D. recipients work in the petroleum industry, and the demand for such workers is only going to increase over the next 25 years (AGI, 2009). If we wanted to have good graduate programs, but somehow could take only students who were committed to working just in academia or government, not only would we be limiting our students' options, we would be limiting our own programs. Moreover, when our students do go into industry, they don't undergo personality changes to become evil, and we don't shun them, either. Every company, including the big ones, is the sum of its employees. There is no independent entity apart from the people in the company. Indeed, if we have taught our students wellthat is, if we have taught them to be honorable and ethical-the fact that they go into industry should be heartening in two ways: (a) we've sent honorable and ethical employees to that company, and (b) the company has hired honorable and ethical people who have perhaps the best chance of heading off potential corporate misdeeds because they can work from within. Sure, those students might hold low-level positions at first, but they will work their way up. Meanwhile, they are making good salaries - the best in the geosciences-and saving for their own retirements, all of which benefit the national economy now and in the future.

4. The sponsorship agreements that GSA signs with companies are of great benefit to the Society. Yes, these companies get their names on things, but the benefit accrues mostly to the science and allows GSA to offers services at a lower cost to its members. 
5. Our civilization is based on the use of natural resources and will continue to be dependent on them for a very long time. Our responsibility is to make sure that we continue to develop means of extraction that are less environmentally damaging and means of remediation that are more effective. We are the best-qualified people to do this, and our students are the best ones to carry these methods into the companies that do the work. The demand for resources will not go away, and the companies will not stop meeting that demand just because some parts of the process offend our sensibilities. It is our responsibility to make sure that the demand is met as safely and responsibly as possible.

Do all the employees of companies behave honorably and ethically? No, and we have seen the scandals. But I want to make a few additional observations. First, we only hear about scandals in big companies for the very reason that if it happens within a big company, it's news-everything, including the amount of money involved, is scaled up. But small companies are just as susceptible_arguably more so because of the lower level of scrutiny-to corporate misdeeds. There is nothing inherently bad about big companies. They're just big. Second, we hear about these things, and the miscreants are caught and punished. If ever there were a glass-half-full situation, it's this. Third, our students who are now employees don't like it any more than we do; when they reach positions of power within their companies, they can influence the corporate decision making. Fourth, those who hold mutual funds

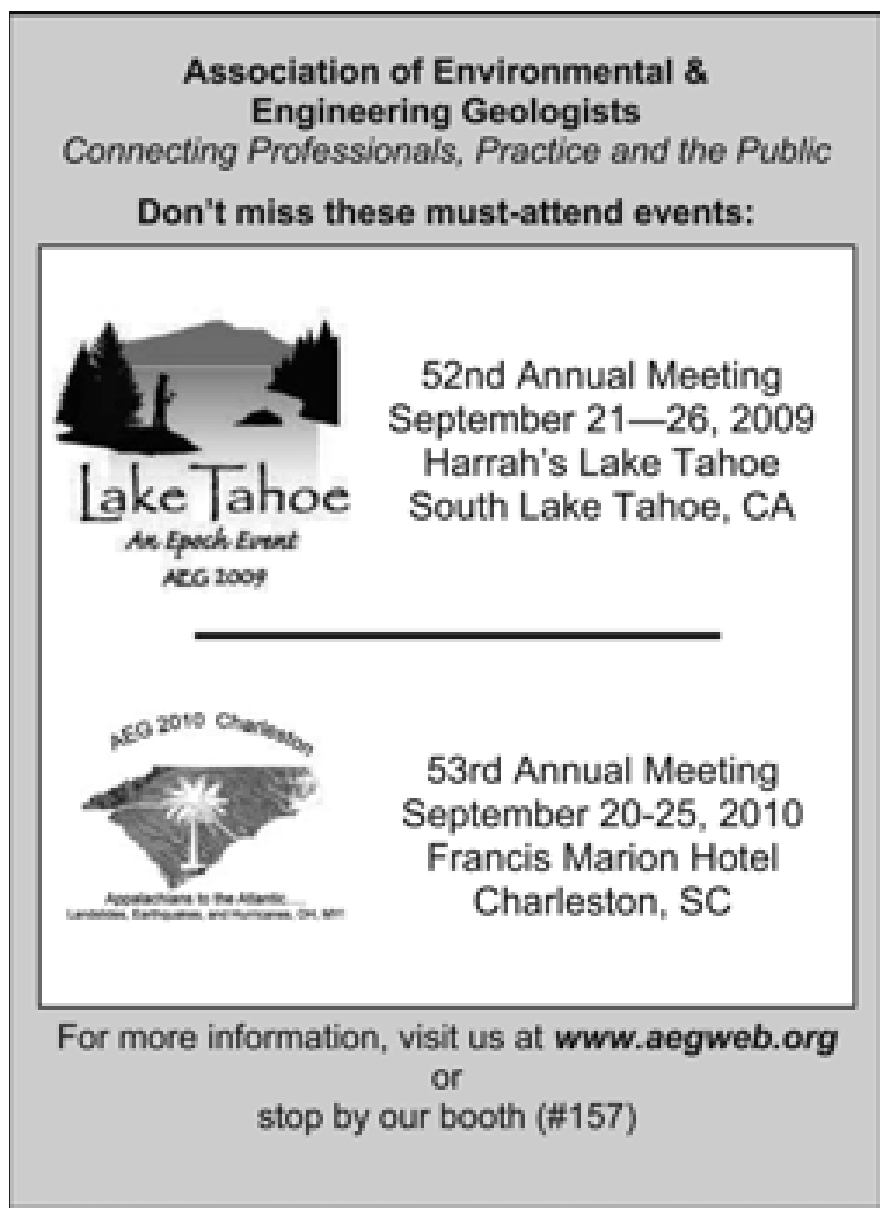

in stocks benefit from the success of large companies. We can hold the feet of our fund managers to the fire to do their due diligence in ensuring that corporate management is honorable and ethical. Our collective power as stockholders is enormous. Just ask those companies who have run afoul of Calpers (managers of the enormous California public retirement system) or CREF (College Retirement Equities Fund, in which many professors have their 403[b]s)! Finally, no institution is immune. Universities have had scandals. Even GSA had its own corporate scandal a few years ago, and only in the last couple of years can we say we've fully recovered and set into place the structure that will prevent such an occurrence again. Does that mean universities and GSA are evil? No, of course not.

Like most of you, I'm not particularly happy with CEO compensation and the wage gap, but, again, our power as stockholders and our students' power as employees can change things - these are already matters of intense debate in the business world, and we are beginning to see some deliberate changes. In the meantime, dissociating ourselves from industry would be like throwing the baby out with the bathwater. The energy some of our members put into excoriating the association with our colleagues in industry is misplaced and should be directed toward making sure that the managers of companies honor their obligation to behave well.

\section{REFERENCES CITED}

American Geological Institute (AGI), 2009, Status of the Geoscience Workforce: Washington, D.C., American Geological Institute (See especially Chapter 3, Geoscience Employment Sectors).

Diamond, J.S., 2004, Collapse: New York, Viking Adult, 592 p.

\section{CSA Connection GSA E-News Ready when you are!}

GSA Connection, GSA's monthly e-news magazine, brings you current information on GSA programs, meetings, and events; books and journals; award deadlines; government and international affairs news; media coverage; and more.

\section{Read it Now}

@

www.geosociety.org/GSA_Connection 